\title{
PLASMA AND URINARY STEROIDS AFTER HYDROCORTISONE INFUSION ${ }^{1}$
}

\author{
BY GEORGE SAYERS, E. MYLES GLENN, K. L. SYDNOR, MARION LIPSCOMB, \\ M. L. SWEAT, LUTHER W. KELLY, JR., RICHARD P. LEVY, AND \\ W. MCK. JEFFERIES
}

\begin{abstract}
(From the Departments of Physiology and Medicine, Western Reserve University School of Medicine, Cleveland, Ohio)
\end{abstract}

(Submitted for publication March 11, 1955; accepted July 11, 1955)

The experiments presented in this report were designed to determine the rate of disappearance of intravenously administered hydrocortisone in patients with Addison's disease before routine steroid therapy had been initiated, during therapy and after therapy had been withdrawn. The results of a similar study have been reported recently by Hellman, Bradlow, Adesman, Fukushima, Kulp, and Gallagher (1). These workers measured changes in radioactivity of the blood following the infusion of $\mathrm{C}^{14}$-labelled hydrocortisone. We have analyzed plasma for hydrocortisone by a method which combines resolution on a silica gel column with quantitation by fluorescence. We have also determined the rate of excretion of those free and conjugated steroids which have a 17,21-dihydroxy20-ketone group. ${ }^{2}$

\section{METHODS}

One hundred mg. of hydrocortisone ${ }^{3}$ (free alcohol) in $500 \mathrm{ml}$. of 5 per cent glucose were infused into an antecubital vein during a period of 20 to 40 minutes. Plasma hydrocortisone was analyzed by the fluorescent method of Sweat $(3,4)$. Urine samples were collected via indwelling catheters and analyzed for free and conjugated 17,21-dihydroxy-20-ketones by the method of Glenn and Nelson (5). Plasma and urine samples were obtained for steroid analyses at the times designated in Tables I, II, and III. The fluorescent method is relatively specific for hydrocortisone (4) and, in the present study, where high levels of hydrocortisone were in-

1 This investigation was supported by a grant from the National Institute of Arthritis and Metabolic Diseases of the National Institutes of Health, U. S. Public Health Service.

2 The results of this study were presented at the Fall Meeting of the American Physiological Society, Madison, Wisconsin, September, 1954 (2).

8 Generous gifts of Dr. H. F. Hailman of the Upjohn Company and of Dr. E. Alpert of Merck and Company. duced, is undoubtedly a reliable index of the concentration of this steroid in peripheral blood. The method for urinary steroids measured the total quantity of those corticosteroids with hydroxy at positions 17 and 21 , and ketone at 20 ; the phenylhydrazine reagent reacts with these substances to give an absorption maximum at 400. $\mathrm{m} \mu$. An important feature of the method is the use of a Florisil column to eliminate the noncorticosteroid phenylhydrazine-reactive materials which are present in a chloroform extract of urine.

Three infusion studies were conducted on each of two patients with Addison's disease and one on a patient with presumably normal adenohypophyseal and adrenocortical function. The first infusion of hydrocortisone was given before replacement therapy was instituted. The second infusion was given approximately one month later during which time the patient received oral hydrocortisone therapy, $5 \mathrm{mg}$. every six hours. Four hours elapsed between the last oral dose of hydrocortisone and the infusion. The third infusion was given 48 hours after the second infusion; the patients received no steroid between the second and the third infusion tests.

Patient $V$. A 42-year-old Negro was admitted with pulmonary tuberculosis. He exhibited signs and symptoms which suggested adrenocortical insufficiency. Intravenous ACTH failed to induce an eosinopenia or to increase peripheral blood corticosteroids. The patient became acutely ill (pulse 160 to 180 ; blood pressure 70/52; disoriented; febrile) and he was given the first infusion of $100 \mathrm{mg}$. of hydrocortisone. He had not received steroid prior to this infusion. The patient's condition remained serious one hour after completion of hydrocortisone administration and he was given a supplementary dose of steroid (100 mg. hydrocortisone in $\mathbf{5 0 0}$ ml. of 5 per cent glucose).

Patient J. A 46-year-old male Negro exhibited the characteristic signs and symptoms of Addison's disease. Intravenous ACTH failed to induce an eosinopenia or to increase peripheral blood corticosteroids. On April 18 , patient $\mathrm{J}$ received $100 \mathrm{mg}$. of cortisone intramuscularly. The first infusion was given on April 29th.

Patient $R$ had apparently normal adrenal and pituitary function. The patient had a congenital cardiac anomaly and was asymptomatic throughout the experimental period. The patient received no steroid prior to infusion of hydrocortisone. 
TABLE I

Plasma and urine steroids before and after hydrocortisone ( $F$ ) infusion in a patient with Addison's disease (patient V)

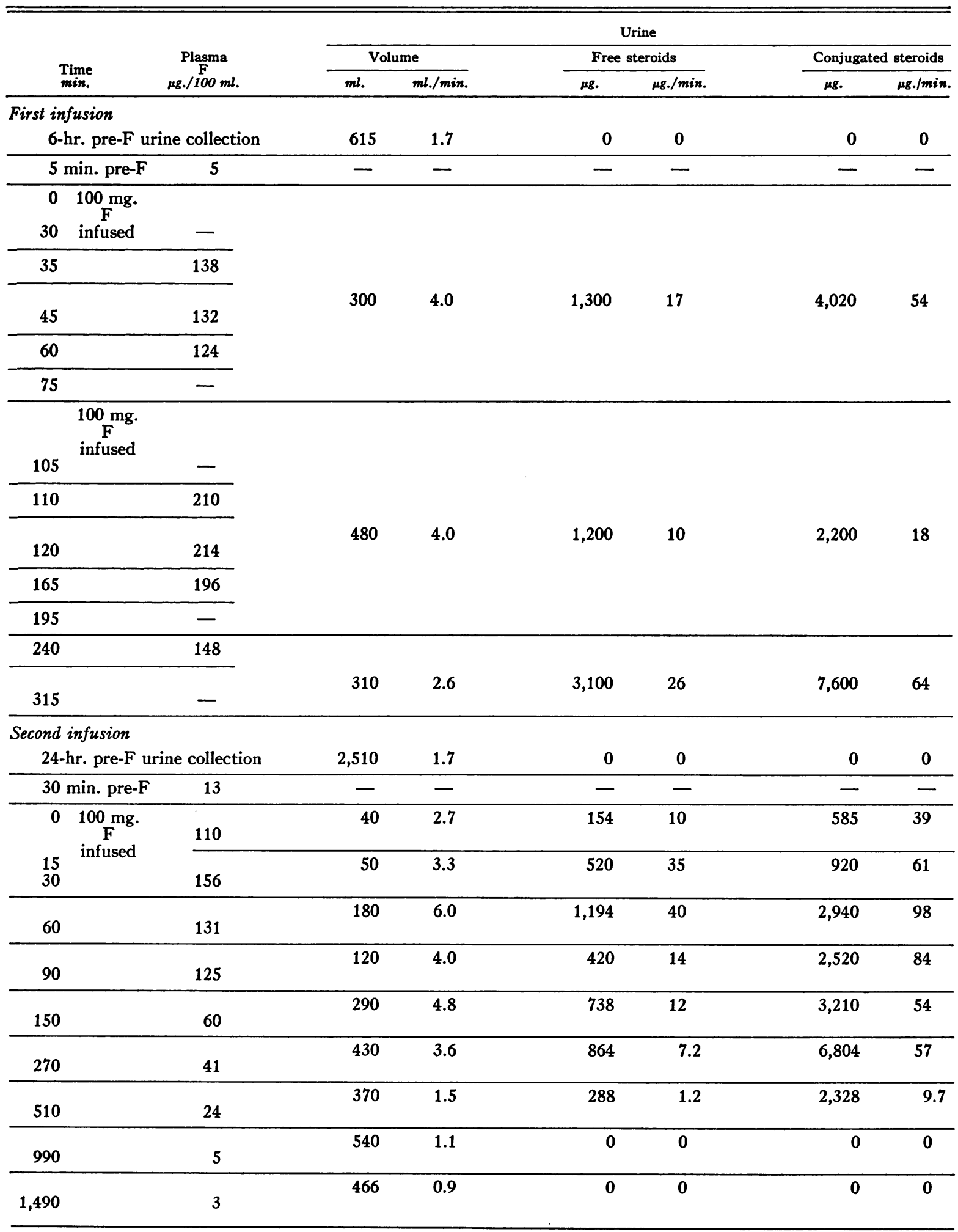


TABLE I-Continued

\begin{tabular}{|c|c|c|c|c|c|c|c|c|}
\hline \multirow{3}{*}{\multicolumn{2}{|c|}{$\begin{array}{l}\text { Time } \\
\text { min. }\end{array}$}} & \multirow{3}{*}{$\begin{array}{c}\begin{array}{c}\text { Plasma } \\
\mathrm{F} \\
\mu \mathrm{g} . / 100 \mathrm{ml} .\end{array} \\
\end{array}$} & \multicolumn{6}{|c|}{ Urine } \\
\hline & & & \multicolumn{2}{|c|}{ Volume } & \multicolumn{2}{|c|}{ Free steroids } & \multicolumn{2}{|c|}{ Conjugated steroids } \\
\hline & & & $m l$. & $m l . / m i n$. & $\mu g$. & $\mu g . / \min$. & $\mu g$. & $\mu g . / \min$ \\
\hline \multicolumn{9}{|c|}{ Third infusion } \\
\hline \multicolumn{3}{|c|}{$\begin{array}{l}\text { 24-hr. pre-F urine collection } \\
5 \mathrm{~min} \text {. pre-F }\end{array}$} & 2,476 & 1.9 & $\underline{0}$ & $\underline{0}$ & $\underline{0}$ & $\underline{0}$ \\
\hline \multirow{2}{*}{\multicolumn{2}{|c|}{$\begin{array}{rr}0 & 100 \mathrm{mg} . \\
15 & \begin{array}{c}\mathrm{F} \\
\text { infused }\end{array} \\
30 & \end{array}$}} & 76 & 20 & 1.3 & 120 & 8.0 & 624 & 42 \\
\hline & & 106 & 30 & 2.0 & 592 & 39 & 532 & 35 \\
\hline 60 & & 73 & 80 & 2.7 & 960 & 32 & 2,703 & 90 \\
\hline 103 & & 54 & 80 & 1.9 & 375 & 8.7 & 1,620 & 38 \\
\hline 150 & & 35 & 200 & 4.3 & 1,289 & 27 & 4,296 & 91 \\
\hline 270 & & 40 & 500 & 4.6 & 864 & 7.2 & 5,136 & 43 \\
\hline 510 & & 25 & 600 & 2.5 & 264 & 1.1 & 5,904 & 25 \\
\hline 990 & & 11 & 430 & 0.9 & 0 & 0 & 0 & 0 \\
\hline 1,410 & & 7 & 375 & 0.9 & 0 & 0 & 0 & 0 \\
\hline 2,950 & & 7 & 2,365 & 1.6 & 0 & 0 & 0 & 0 \\
\hline
\end{tabular}

TABLE II

Plasma and urine steroids before and after hydrocortisone $(F)$ infusion in a patient with Addison's disease (patient $J$ )

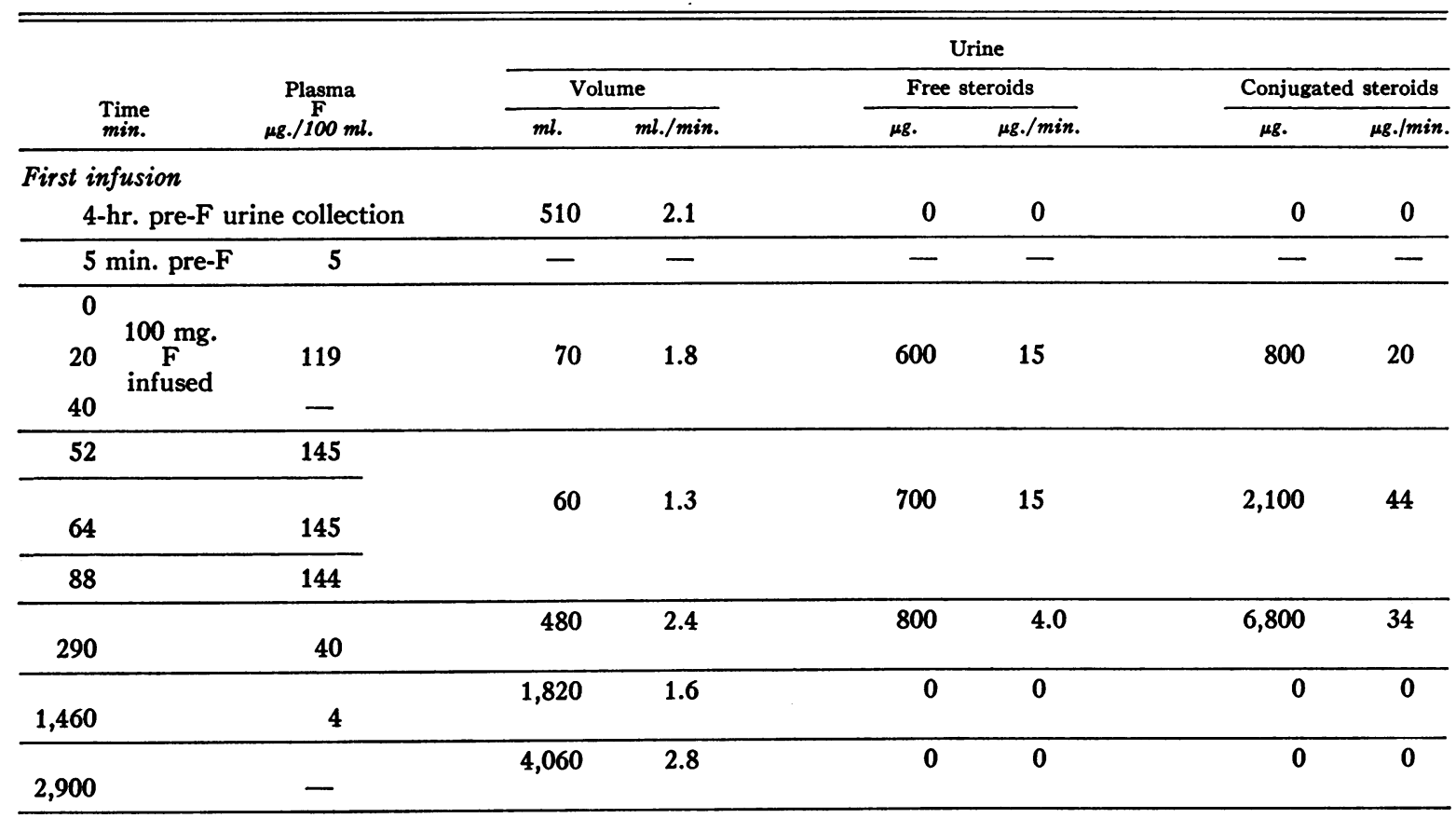


TABLE II-Continued

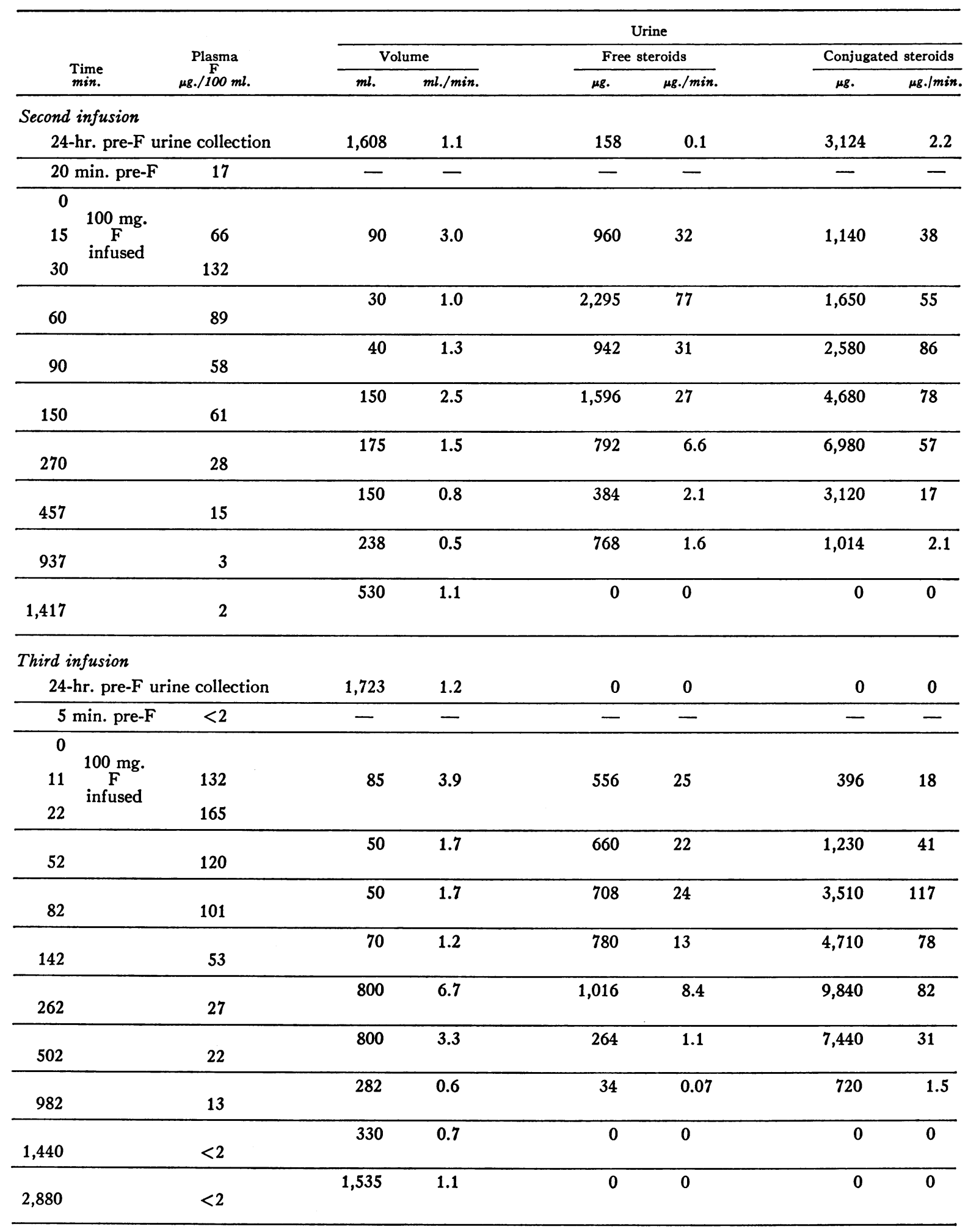


TABLE III

Plasma and urine steroids before and after hydrocortisone $(F)$ in a patient with normal adrenal function (patient $R$ )

\begin{tabular}{|c|c|c|c|c|c|c|c|}
\hline \multirow{3}{*}{$\begin{array}{l}\text { Time } \\
\text { min. }\end{array}$} & \multirow{3}{*}{$\begin{array}{c}\text { Plasma } \\
\mathbf{F} \\
\mu \mathrm{g} . / 100 \mathrm{ml} .\end{array}$} & \multicolumn{6}{|c|}{ Urine } \\
\hline & & \multicolumn{2}{|c|}{ Volume } & \multicolumn{2}{|c|}{ Free steroids } & \multicolumn{2}{|c|}{ Conjugated steroids } \\
\hline & & $m l$. & $m l . / m i n$. & $\mu g$. & $\mu g . / \min$. & $\mu g$. & $\mu g . / \min$. \\
\hline \multicolumn{2}{|c|}{ 24-hr. pre-F urine collection } & 1,290 & 0.9 & 0 & 0 & 4,032 & 2.8 \\
\hline 5 min. pre-F & 13 & - & - & - & - & - & - \\
\hline $\begin{array}{rc}0 & 100 \mathrm{mg} . \\
15 & \mathrm{~F}\end{array}$ & 94 & 55 & 3.6 & 406 & 27 & 807 & 54 \\
\hline 30 & 102 & 24 & 1.6 & 696 & 46 & 766 & 51 \\
\hline 60 & 54 & 112 & 3.7 & 552 & 18 & 2,676 & 89 \\
\hline 90 & 40 & 140 & 4.7 & 420 & 14 & $1 ; 440$ & 48 \\
\hline 150 & 60 & 315 & 5.3 & 720 & 12 & 3,060 & 51 \\
\hline 270 & 45 & 155 & 1.3 & 480 & 4.0 & 5,040 & 42 \\
\hline 510 & 13 & 190 & 0.8 & 336 & 1.4 & 5,520 & 23 \\
\hline 990 & 8 & 320 & 0.7 & 48 & 0.1 & 4,512 & 9.2 \\
\hline 1,470 & 15 & 360 & 0.8 & 48 & 0.1 & 1,392 & 2.9 \\
\hline 2,910 & 12 & 1,228 & 0.9 & 0 & 0 & 187 & 0.1 \\
\hline
\end{tabular}

\section{RESULTS AND DISCUSSION}

\section{Pre-infusion levels of plasma hydrocortisone}

In the patients with Addison's disease the highest pre-infusion level of plasma hydrocortisone was obtained prior to the second infusion and was of the same order of magnitude as that obtained in the subject with normal adrenals (Tables I, II, and III).

Values of $5 \mu \mathrm{g}$. per $100 \mathrm{ml}$. were obtained in the patients with Addison's disease at a time when they had not been treated with hormone therapy. These results must be interpreted with caution. Although the problem of steroid concentration in Addison's disease as compared to normal subjects is not the subject of this study a short comment is in order. On the one hand, a substance in plasma may interfere and give a constant background reading in the analyses of hydrocortisone. On the other hand, patients with Addison's disease may vary in regard to the degree of adrenocortical insufficiency. Small masses of adrenocortical tissue may secrete steroid in sufficient quantity to maintain fixed minimal levels of hydrocortisone. This tissue may be presumed to be secreting at a maximum rate at all times. In response to a stressful stimulus no increase in rate of production of steroid will occur. Eik-Nes, Sandberg, Migeon, Tyler, and Samuels (6) have observed patients with Addison's disease who exhibited normal levels of 17 hydroxycorticoids. These patients did not respond to ACTH with an elevation of blood steroid. The two patients observed in this study also did not respond to ACTH with an elevation of blood steroids (7). The problem has important implications from the standpoint of micromethods for analysis of steroids and from the standpoint of the pathological physiology of Addison's disease. No definite conclusion may be made at this time. Additional studies must be conducted to test the absolute specificity of the micromethods at low concentrations of blood steroids. 


\section{Infusion levels of plasma hydrocortisone}

As expected, the concentration of hydrocortisone in the plasma increased rapidly during infusion of $100 \mathrm{mg}$. of this steroid over a period of 30 minutes (Figures 1-7). The average concentration was $135 \mu \mathrm{g}$. per $100 \mathrm{ml}$. at the end of the infusion in seven tests. (Included in the average are two samples, one taken at 5 , the other at 12 minutes after the end of the infusion.) In the patients with Addison's disease the levels of hydrocortisone at the end of the first infusions (138,

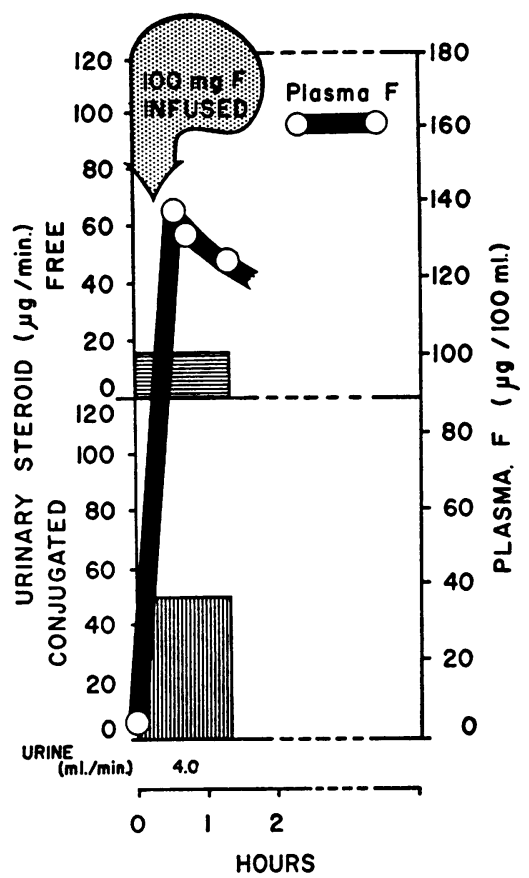

Fig. 1. Plasma Hydrocortisone and Urinary Free ANd Conjugated 17,21-Dihydroxy-20-Ketones in PATIENT V (ADDISON's DISEASE) AFTER First Infusion OF 100 Mg. OF HYdROCORTISONE

Patient had received no steroid therapy prior to first infusion.

$145 \mu \mathrm{g}$. per $100 \mathrm{ml}$.) do not appear to be significantly different from those obtained at the end of the second $(156,132 \mu \mathrm{g}$. per $100 \mathrm{ml}$.) or at the end of the third infusion $(106,165 \mu \mathrm{g}$. per 100 $\mathrm{ml}$.). The concentration of hydrocortisone at the end of infusion in the normal subject, $102 \mu \mathrm{g}$. per $100 \mathrm{ml}$., was the lowest value obtained. The tentative conclusion appears warranted that a deficiency of cortical steroids is not associated with an accelerated rate of disappearance of hydrocor-

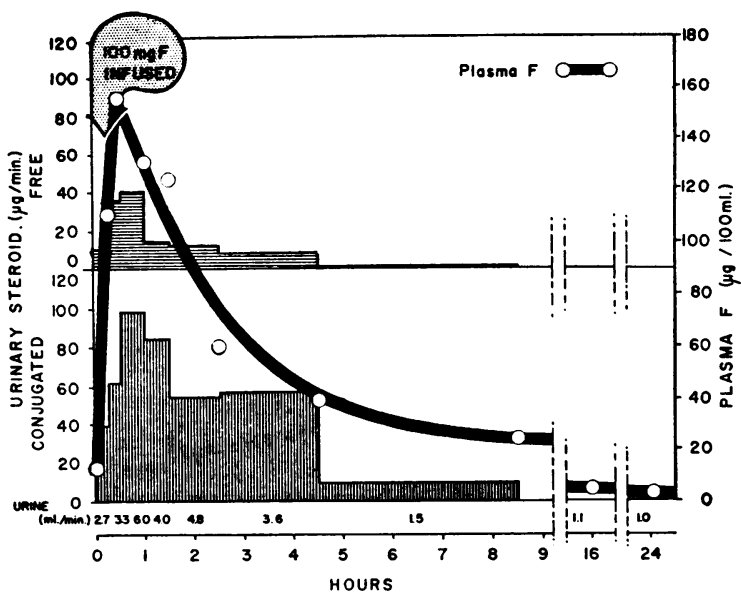

Fig. 2. Plasma Hydrocortisone and Urinary Free And Conjugated 17,21-Dihydroxy-20-Ketones in PATIENT V (ADDISON's Disease) AFTER Second Infusion of 100 MG. OF HYDROCORTISONE

Patient was on hydrocortisone therapy $(5 \mathrm{mg}$. every six hours) for one month between first and second infusions.

tisone from the plasma when a large dose of the steroid is infused over 30 minutes.

The rapidity of exit of infused hydrocortisone from the vascular compartment is dramatically illustrated by a simple calculation. The average concentration of hydrocortisone at the end of infusion was $135 \mu \mathrm{g}$. per $100 \mathrm{ml}$. or $1.35 \mathrm{mg}$. per liter. The total quantity in the plasma at the end

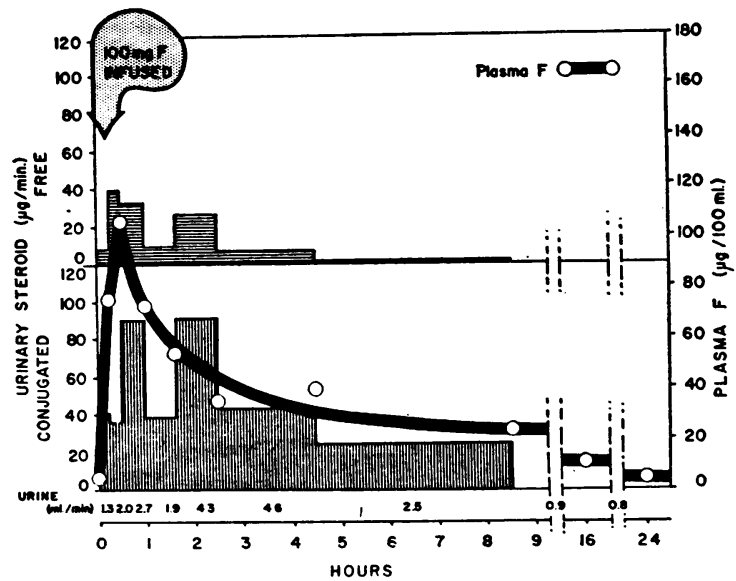

Fig. 3. Plasma Hydrocortisone and Urinary Free ANd Conjugated 17,21-Dihydroxy-20-Ketones in PATIENT V (ADDISON's DISEASE) AFTER Third Infusion of 100 MG. OF HYDROCORTISONE

Forty-eight hours elapsed between second and third infusions during which time patient received no steroid therapy. 


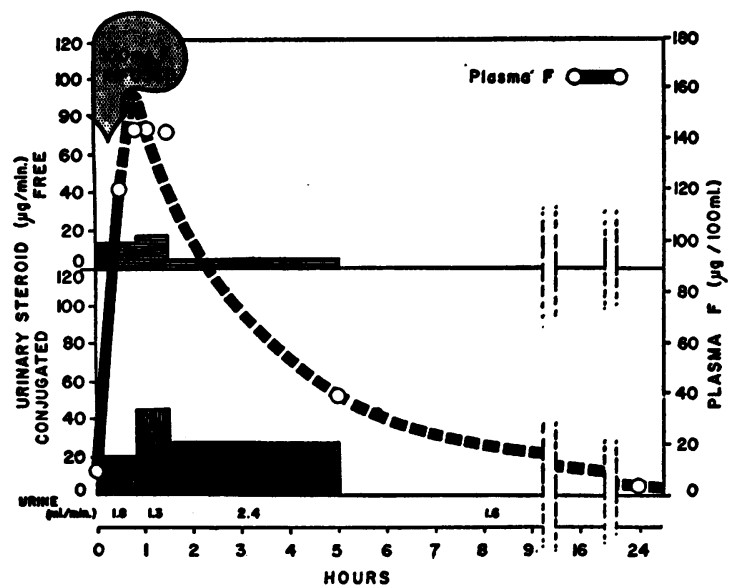

Fig. 4. Plasma Hydrocortisone and Urinary Free and Conjugated 17,21-Dihydroxy-20-Ketones in PaTIENT J (AdDISON's DISEASE) AFTER First Infusion OF 100 MG. OF HYDROCORTISONE

Patient had received only one dose of steroid prior to first infusion (100 mg. of cortisone were given intramuscularly 11 days before the first infusion).

of the infusion equals $1.35 \mathrm{mg}$. per liter times 3 liters (plasma volume), or $4 \mathrm{mg}$. Hence, of the $100 \mathrm{mg}$. infused, only $4 \mathrm{mg}$. remained in the total volume at the end of the 30 -minute infusion. Less than $2 \mathrm{mg}$. of free steroid was excreted during the infusion. (See free steroid excretion data in Tables I, II, and III.) The fact that steroid glucuronides were excreted during the infusion

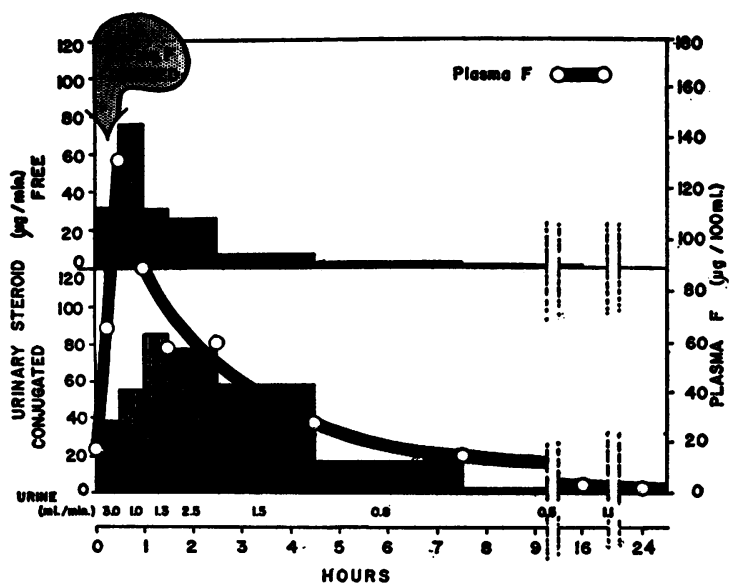

Fig. 5. Plasma Hydrocortisone and Urinary Free ANd Conjugated 17,21-Dihydroxy-20-Ketones in PaTIENT J (ADDison's Disease) AFTER Second Infusion of 100 MG. OF HYDROCORTISONE

Patient was on hydrocortisone therapy $(5 \mathrm{mg}$. every six hours) for one month between first and second infusions.

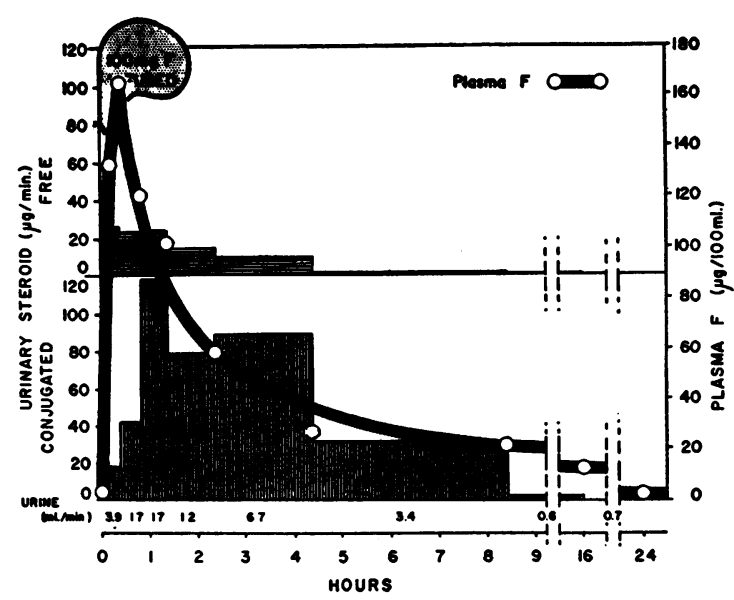

Fig. 6. Plasma Hydrocortisone and Urinary Free ANd Conjugated 17,21-Dihydroxy-20-Ketones in PATIENT J (ADDISON's DISEASE) AFTER Third Infusion of 100 MG. OF HYDROCORTISONE

Forty-eight hours elapsed between second and third infusions, during which time patient received no steroid therapy.

suggests that free hydrocortisone rapidly enters cells and is conjugated with glucuronic acid. Hellman and his co-workers (1) presented data for radioactivity of hydrocortisone in blood for one of their six experiments. In the other five experiments the radioactivity represented the sum of hydrocortisone and its degradation products. A dose of $0.25 \mathrm{mg}$. of hydrocortisone with an activity of 0.940 microcurie ( $\mu c$.) was injected.

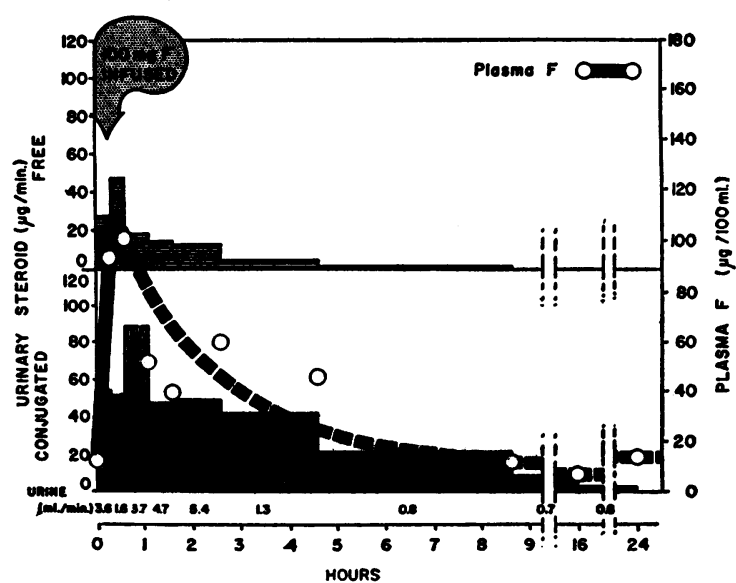

Fig. 7. Plasma Hydrocortisone and Urinary Free and Conjugated 17,21-Dihydroxy-20-Ketones in PAtient $R$ (Normal Pituitary-Adrenocortical FuncTION) AFTER INFUSION OF 100 MG. OF HyDROCORTISONE

Patient had not received steroid therapy prior to infusion. 
Fifteen minutes after the end of the infusion the activity of hydrocortisone plus degradation products in blood was $0.021 \mu \mathrm{c}$. per liter. For a blood volume of 6 liters total activity in the vascular compartment equals $.126 \mu \mathrm{c}$. A maximum of 15 per cent of this radioactivity was present as unaltered hydrocortisone. Therefore, approximately 2 per cent of the injected hydrocortisone was present after 15 minutes, a figure which agrees with our values obtained in 7 experiments. Our observations are also in agreement with those of Brown, Willardson, Samuels, and Tyler (8).

\section{Post-infusion levels of plasma hydrocortisone}

The post-infusion period is characterized by a rapid reduction in the concentration of hydrocortisone in the plasma (Figures 1-7). The half-life of hydrocortisone, the time after the end of infusion for the plasma concentration to decrease to one-half, was estimated in four tests: Patient V, second infusion, two and one-third hours (Figure 2) ; patient $\mathrm{V}$, third infusion, one and threefourth hours (Figure 3 ) ; patient $\mathrm{J}$, second infusion, two hours (Figure 5); patient $\mathrm{J}$, third infusion, one and one-third hours (Figure 6). The estimates are remarkably uniform when one considers the complexity of processes, urinary excretion, biliary excretion, degradation, diffusion, selective concentration in certain tissues and conjugation, which must be involved in the disappearance of steroids from the plasma. Brown, Willardson, Samuels, and Tyler infused $1 \mathrm{mg}$. of hydrocortisone per $\mathrm{Kg}$. over 30 minutes. The halflife of the steroid estimated from their observations is in excellent agreement with the results of this study.

Unfortunately, adequate numbers of samples were not obtained in the first infusion tests on the patients with Addison's disease for accurate estimates of half-life. Patient $\mathrm{V}$ was given a supplementary infusion at the first test which complicated the study (Figure 1 ). In patient $\mathrm{J}$, the half-life in the first infusion test as estimated from the limited data available does not appear to be less than that of the patients with Addison's disease in the second or third tests (Figure 4). The post-infusion values for plasma hydrocortisone in the patient with normal adrenals (patient $R$ ) do not follow a consistent enough pattern to warrant the estimation of half-life (Figure 7).
The $\log$ of the concentration of plasma hydrocortisone in four tests (second and third tests on patients $\mathrm{J}$ and $\mathrm{V}$ ) has been plotted against time in Figure 8. No simple rectilinear relationship exists between these two variables. The curve indicates that at least two processes are involved in the disappearance of hydrocortisone. As stated above, of the $100 \mathrm{mg}$. injected, only $4 \mathrm{mg}$. of hydrocortisone remained in the total plasma volume at the end of infusion.

\section{Urinary excretion of steroids}

Free steroids. In the 24 hours prior to the first, the second, or the third infusion tests, no significant quantity of free 17,21-dihydroxy-20-ketones was excreted by any subject except patient $J$, who excreted $158 \mu \mathrm{g}$. during the 24 hours prior to the second test (Tables I, II, and III). $\mathrm{Pa}$ tient $\mathrm{R}$ with normal adrenal function did not excrete a detectable quantity of free steroid in the 24 hours prior to the infusion. These observations indicate that exceedingly small quantities of hydrocortisone and related steroids are excreted in the free form in normal subjects or in patients with Addison's disease given maintenance doses of hydrocortisone.

The peak rate of excretion of free 17,21-dihydroxy-20-ketones was attained during the infusion of hydrocortisone or in the 30-minute collection period which immediately followed (Tables I, II, and III, and Figures 1-7). The subsequent values for rate of excretion of free steroids paral-

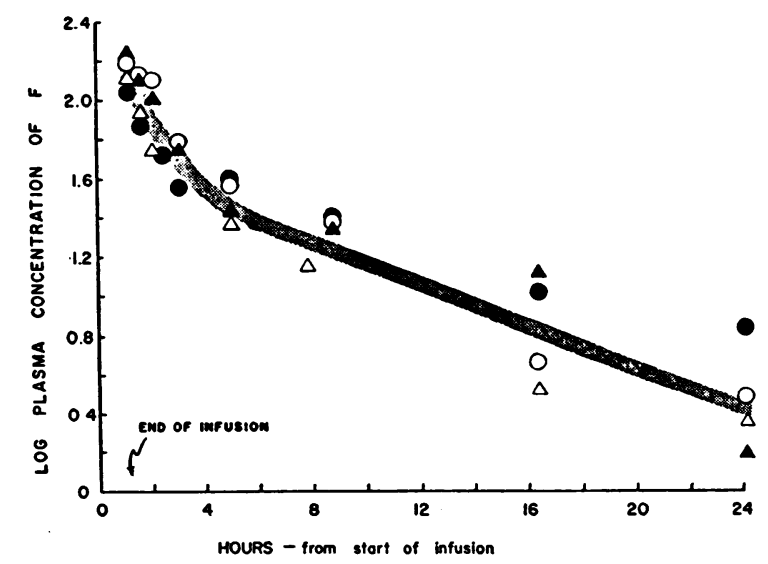

Fig. 8. Log of Plasma Hydrocortisone Concentration Plotted against Time for Four Infusion Tests

$\mathrm{O}$-second infusion in patient $\mathrm{V}$; - -third infusion in patient $\mathrm{V} ; \Delta-$ second infusion in patient $\mathrm{J} ; \Delta$-third infusion in patient $\mathrm{J}$. 


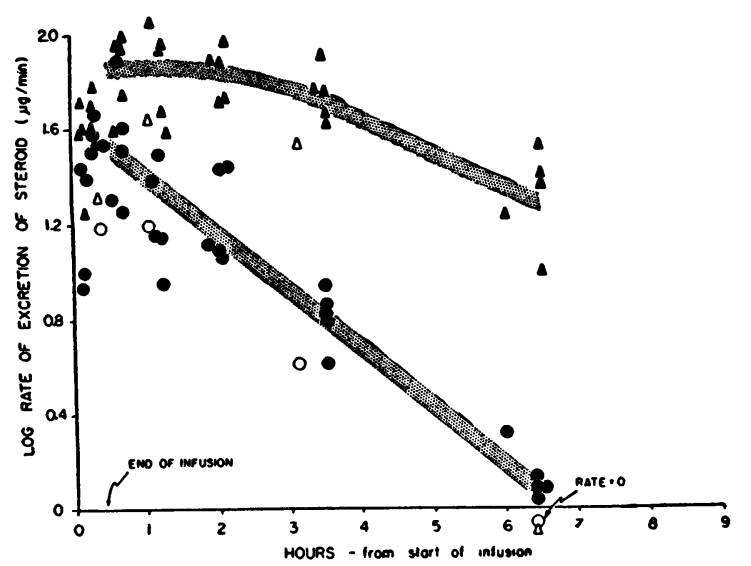

Fig. 9. Log of the Rate of Urinary Excretion of Free and of Conjugated 17,21-Dinydroxy-20-Ketones Plotted against Time

- -free and $\Delta$-conjugated steroids for all infusions except the first infusion in patient $\mathrm{J}$, in which designations are $O$ and $\Delta$.

leled the plasma levels of hydrocortisone except for the third infusion test on patient $V$ for the 60 to 103-minute period following infusion.

Approximately 4 per cent of the administered steroid can be accounted for as free 17,21-dihydroxy-20-ketones excreted in the 24 hours following the infusion. Patient $\mathrm{J}$ excreted a smaller quantity of free steroid during the first test as compared to the amounts excreted during the second and third tests.

The first test on patient $\mathrm{V}$ was complicated by a second infusion of steroid. However, it is of interest to compare the rate of excretion in all tests during the first 75 minutes after the beginning of infusion (the time at which a second infusion was started in the first test on patient V). During the first 75 minutes, $1,300,2,078$, and $1,803 \mu \mathrm{g}$. of free steroid were excreted by patient $\mathrm{V}$ during the first, second, and third tests, respectively. The corresponding figures for patient $J$ are $1,105,3,726$, and $1,768 \mu \mathrm{g}$. For patient $\mathrm{R}$ the amount excreted was $1,864 \mu \mathrm{g}$. The reduction of steroid excretion in the pre-therapy tests suggests a defect in renal excretion since the blood levels of free hydrocortisone were not different from those observed in the other tests. Glomerular filtration rate is reduced in severe adrenocortical insufficiency (9) and may account for the observed reduction in the rate of excretion of free steroids. In Figure 9, $\log$ of the rate of excretion of free steroids in micrograms per minute has been plotted against time. The estimated time for the process to be reduced to one-half its peak rate is one and one-half hours, a value which corresponds quite closely with the half-life of hydrocortisone in the plasma.

Conjugated steroids. No significant quantity of conjugated steroid was excreted by the two patients with Addison's disease in the pre-infusion periods except in the case of patient $\mathrm{J}$ who excreted $3,124 \mu \mathrm{g}$. in the 24 hours prior to the second test (Tables I and II). The subject with normal adrenals excreted 4,032 $\mu \mathrm{g}$. (Table III). No explanation can be offered as to why patient $\mathrm{V}$ did not excrete conjugated steroids at a time when he was receiving $5 \mathrm{mg}$. of hydrocortisone by mouth, six times per day.

That the process of conjugation occurs at a remarkably rapid rate is indicated by the fact that conjugated steroids appeared in the urine in relatively large quantities during the first 15 minutes of the infusion (see Tables and Figures). However, the peak rate of excretion of the conjugated steroids usually occurred in the period immediately following the establishment of the peak rate of excretion of the free steroids.

The conjugates excreted during the 24 hours following infusion accounted for approximately 20 per cent of the injected steroid. Patient J excreted only 9.7 per cent of the administered steroid as conjugates in the first test as compared to 21.2 and 27.8 per cent in the second and third tests. The patient with normal adrenals excreted 25.4 per cent of the infused hydrocortisone.

During the first 75 minutes after the start of the infusion, patient $\mathrm{V}$ excreted 4,026, 5,705, and $4,429 \mu \mathrm{g}$. in the first, second, and third tests, respectively. The corresponding figures for patient $\mathrm{J}$ were $2,340,4,080$, and $4,317 \mu \mathrm{g}$. Patient $\mathrm{R}$ excreted $4,969 \mu \mathrm{g}$. As in the case of the free steroid, there appears to be a reduction in renal excretion of conjugated steroids in subjects with Addison's disease given intravenous hydrocortisone at a time when they have had no previous steroid therapy. The reduced rate of excretion could be due to a renal impairment or to a defect in the rate of conjugation of hydrocortisone. According to Hellman and his associates (1), renal excretion of total steroids as measured by radioactivity was normal in one patient with Addison's disease who 
had received no therapy for 48 hours prior to infusion of hydrocortisone-4-C $C^{14}$. This is in agreement with our findings.

In Figure 9, $\log$ of the rate of excretion of conjugated steroids in micrograms per minute has been plotted against time. The half-life is estimated to be four hours, a value in agreement with that of Hellman and his associates for the half-life of free and conjugated combined. It should be emphasized that we measured steroids with a 17,21-dihydroxy-20-ketone group, whereas Hellman and his associates measured all steroids with $\mathrm{C}^{14}$ in ring $\mathrm{A}$.

\section{COMMENT}

The adrenal cortex plays an important role in the resistance of the organism to environmental change. The patient with Addison's disease or the adrenalectomized animal succumbs to any one of a great variety of stresses which the intact animal can readily resist. Furthermore, these same stressful stimuli excite the pituitary adrenocortical system of an intact organism to increase the production of cortical steroids. The important question arises as to why the organism requires supplementary quantities of adrenocorticosteroids to manifest its full capacities to survive a noxious stimulus. The resistance of the animal to certain stressful stimuli may be explained in terms of known metabolic actions of the cortical steroids. However, the mechanism of resistance to the great majority of noxious stimuli remains unexplained. Furthermore, we are unable to answer the question as to whether the functional actions of the adrenocorticosteroids are coupled with a chemical transformation in these substances. Sayers, in a review (10) of this problem, was inclined to the view that adrenocorticosteroids are "utilized" at an accelerated rate during stress. However, that he was aware of the inadequacy of the experimental evidence for such a concept is borne out by his statement that "whether degradation is a necessary accompaniment of steroid hormone action or is an entirely unrelated and incidental phenomenon is a problem of fundamental importance. Until such time as these points are clarified it is well to apply the word 'utilization' of cortical steroids without any implication as to the relation between degradation and functional activity of the hormone." If by "utili- zation of adrenocorticosteroids" is meant a multitude of processes including excretion, degradation, and concentration in certain tissues, which act to reduce the concentration of these substances in the blood, then the gross metabolic analyses of the present report do not support the thesis that stress increases the rate of "utilization" of adrenocorticosteroids. There was no significant difference between the plasma level of hydrocortisone at the end of infusion of this steroid in the insufficiency test when the patients were in crisis and the plasma level in the test applied at a time when the patient appeared to be in a state of eucorticism. Furthermore, the rate of decline in steroid level in the plasma subsequent to the end of infusion appeared to be the same in all tests. The experiments suggest that severe adrenocortical insufficiency is associated with a renal impairment in the excretion of steroids. However, it is doubtful that this impairment significantly altered the over-all "utilization" of hydrocortisone.

Studies designed to measure rate of disappearance of hydrocortisone from blood and rate of appearance of degradation products in urine, as exemplified by the work of Hellman and his coworkers and the work reported here, do not offer support for the thesis that adrenocorticosteroids are "utilized" at an accelerated rate during stress. However, they do not represent evidence against such a thesis. Strictly degradative processes may go on at a much faster rate than conversions which are coupled with the functional activity of the adrenocorticosteroids. The influence of such conversions on the over-all rate of disappearance of hydrocortisone from the body fluids may be masked by the strictly degradative processes. Both in vivo $(8,11,12)$ and in vitro $(13-15)$ experiments indicate that the liver plays a major role in the disappearance of hydrocortisone from the blood. That the chemical transformations in the liver are not essential for the biological activity of hydrocortisone is suggested by the fact that this steroid can exhibit its metabolic actions in the hepatectomized animal (16). Whether degradation in the liver plus excretion by the kidney can account for all of the hydrocortisone which disappears has not been determined. Until such time as this point is clarified, the concept that stress increases tissue "utilization" of adrenocorticosteroids must be considered with reservation 
as the explanation for the accelerated production of adrenocorticosteroids which accompanies application of a stressful stimulus.

\section{SUMMARY AND CONCLUSIONS}

Hydrocortisone disappears rapidly from the vascular compartment following its intravenous administration. At the end of a 30-minute period of infusion of $100 \mathrm{mg}$. of hydrocortisone only 4 mg. remained in the total plasma volume. The half-life of the steroid, the time for the concentration of plasma hydrocortisone at the end of the infusion to be reduced to one-half, was estimated to be one and one-third to two and onethird hours.

The rate of disappearance of hydrocortisone from the plasma as measured under the conditions of these experiments appears to be uninfluenced by the state of the tissues in regard to adrenocortical hormone. The results do not support the thesis that hydrocortisone disappears more rapidly from the blood in adrenocortical insufficiency as compared to eucorticism. However, gross over-all metabolic studies of this type do not disprove this thesis.

The renal excretion of free steroids with a 17,21-dihydroxy-20-ketone group parallels the plasma concentration of free hydrocortisone. Conjugation to glucuronides occurs rapidly; glucuronides of steroids with a 17,21-dihydroxy-20ketone group were excreted during the first 15 minutes of the infusion. The peak rate of excretion of glucuronides usually occurred in the 30 -minute period following the end of infusion. Subsequently, the rate of excretion remained elevated for three hours and then declined to reach a low level after eight hours.

The major fraction of the free steroids was excreted during the first four hours after infusion of hydrocortisone; the major fraction of the conjugated steroids was excreted during the first eight hours. The free steroids excreted during the 24 hours following infusion accounted for approximately 4 per cent of the administered hydrocortisone; the conjugated steroids accounted for approximately 20 per cent.

The results suggest that renal excretion of free and of conjugated 17,21-dihydroxy-20-ketones is impaired in patients with Addison's disease who have had no previous steroid therapy.

\section{REFERENCES}

1. Hellman, L., Bradlow, H. L., Adesman, J., Fukushima, D. K., Kulp, J. L., and Gallagher, T. F., The fate of hydrocortisone-4-C $\mathrm{C}^{14}$ in man. J. Clin. Invest., 1954, 33, 1106.

2. Glenn, E. M., Sydnor, K. L., Sayers, G., Sweat, M. L., Jefferies, W. M., Levy, R. P., and Kelly, L. W., Blood and urinary steroids after infusion of 17-hydroxycorticosterone. Am. J. Physiol., 1954, 179, 639.

3. Sweat, M. L., Silica gel microcolumn for the chromatographic resolution of corticosteroids. Anal. Chem., 1954, 26, 1964.

4. Sweat, M. L., Sulfuric acid-induced fluorescence of corticosteroids. Anal. Chem., 1954, 26, 773.

5. Glenn, E. M., and Nelson, D. H., Chemical method for the determination of 17-hydroxycorticosteroids and 17-ketosteroids in urine following hydrolysis with $\beta$-glucuronidase. J. Clin. Endocrinol. \& Metab., 1953, 13, 911.

6. Eik-Nes, K., Sandberg, A. A., Migeon, C. J., Tyler, F. H., and Samuels, L. T., Changes in plasma levels of 17-hydroxycorticosteroids during the intravenous administration of ACTH. II. Response under various clinical conditions. J. Clin. Endocrinol. \& Metab., 1955, 15, 13.

7. Sweat, M. L., Adrenocorticosteroids in peripheral and adrenal venous blood of man. J. Clin. Endocrinol. \& Metab., In press.

8. Brown, H., Willardson, D. G., Samuels, L. T.,-and Tyler, F. H., 17-hydroxycorticosteroid metabolism in liver disease. J. Clin. Invest., 1954, 33, 1524.

9. Smith, H. W., The Kidney: Structure and Function in Health and Disease. New York, Oxford University Press, 1951, p. 370 .

10. Sayers, G., The adrenal cortex and homeostasis. Physiol. Rev., 1950, 30, 241.

11. Tomizawa, H. H., Narahara, H. T., Gibbons, C. A., and Williams, R. H., A metabolic study of hydrocortisone in rats. Proc. Soc. Exper. Biol. \& Med., 1954, 85, 51.

12. Nelson, D. H., Determination of adrenal cortical steroids in blood. Conference on Adrenal Cortex, 3d, 1951, Transactions. New York, Josiah Macy, Jr. Foundation, 1952, p. 89.

13. Schneider, J. J., and Horstmann, P. M., Effects of incubating compound $E$ and related steroids with various surviving rat tissues. J. Biol. Chem., 1952, 196, 629.

14. Hechter, O., Solomon, M. M., Macchi, I. A., Caspi, E., and Feinstein, M., Corticosteroid metabolism in isolated perfused rat livers. J. Clin. Endocrinol. \& Metab., 1952, 12, 935.

15. Miller, L. L., and Axelrod, L. R., Cortisone metabolism in the perfused normal and experimental cirrhotic rat liver. Metabolism, 1954, 3, 438.

16. Bondy, P. K., Ingel, D. J., and Meeks, R. C., Influence of adrenal cortical hormones upon the level of plasma amino acids in eviscerate rats. Endocrinology, 1954, 55, 354. 